\title{
Corrosion Resistance Synergistic Appraisal of Titanium- Impregnated Bisphenol A-Type Epoxy Duplex Coating System in Stimulated and Natural Marine Environments of Southeastern Coastal Area of China-Pakistan Economic Corridor
}

\author{
Ishrat Jamil,, ${ }^{1}$ Humaira Bano ${ }^{(D)},{ }^{1}$ Vinod C. Malshe, ${ }^{2}$ Azhar Mahmood $\left(\mathbb{D},{ }^{3}\right.$ Kamran Khan, \\ and Nasir M. Ahmad $\left.{ }^{5}\right)^{5}$ \\ ${ }^{1}$ Department of Chemistry, University of Karachi, Karachi 75270, Pakistan \\ ${ }^{2}$ Paint Technology Section, Institute of Chemical Technology, Matunga, Mumbai 400019, India \\ ${ }^{3}$ School of Natural Sciences, National University of Sciences and Technology, H-12, 44000 Islamabad, Pakistan \\ ${ }^{4}$ Nelson Paints Industries (Pvt.) Ltd., Karachi 74900, Pakistan \\ ${ }^{5}$ Polymer Research Group, School of Chemical and Materials Engineering (SCME), National University of Sciences and Technology, \\ H-12, Islamabad 44000, Pakistan
}

Correspondence should be addressed to Humaira Bano; humairab@uok.edu.pk

Received 23 March 2021; Accepted 26 June 2021; Published 15 July 2021

Academic Editor: Lih-sheng Turng

Copyright ( 92021 Ishrat Jamil et al. This is an open access article distributed under the Creative Commons Attribution License, which permits unrestricted use, distribution, and reproduction in any medium, provided the original work is properly cited.

\begin{abstract}
This research endeavor is aimed at developing a protective coating for marine service conditions of the southeastern coastal area of the China-Pakistan Economic Corridor. Bisphenol A-type epoxy-based protective coatings were prepared by impregnating exotic titanium metal microparticles into two different proportions, i.e., $5 \%$ and $10 \%(w / w)$. Film hardness measurement by pencil test, adhesion measurement by the crosshatch-tape test, chemical and heat resistance test, gloss measurement, natural exposure, and salt spray testing have demonstrated that Ti-enriched coatings have performed better than the virgin epoxy coating. Moreover, scanning electron microscopy has depicted more surface degradation. Fourier transform infrared spectroscopy has indicated higher mass loss and chain scission in the virgin epoxy coating than the Ti-enriched coatings. In addition, these Ti microparticles have filled up the cavities/imperfections, reduced cracking, promoted crosslinking during the curing, and cordoned-off passage of corrodents and moisture, thus improving epoxy resin coating features. These results have widened the scope of Ti-embedded epoxy coatings against atmospheric corrosion for highly corrosive marine sites.
\end{abstract}

\section{Introduction}

Corrosion is a severe technical problem that has a significant financial impact on the economy. The application of paints and coatings on metallic surfaces is a cost-effective and most widely used method for corrosion control [1-7]. Among different coatings, epoxy coatings are well known for their durability, flexibility, high resistance to heat and chemicals, ease of application, and best adhesion [5]. However, it shows poor resistance in the highly corrosive marine environment due to the initiation of defects and impairments in the mechanical properties of the epoxy coating system [6]. Due to these defects, diffusion of moisture, oxygen, and atmospheric pollutants are prompted, resulting in the delamination of the coatings and corrosion of the metallic substrate $[4,5]$. These coatings' performance features and application spectrum have been reported to be improved by adding various dispersed metallic phases into the resin. It also reduces the cost and increases the service life of the metallic substrate by providing long-lasting protection [4]. Brostow et al. have observed the improvement in the tribology and surface energy of the epoxy coating by the addition of microsized metal powders including $\mathrm{Ni}, \mathrm{Al}, \mathrm{Ag}$, and $\mathrm{Zn}$ [4]. Muszynska et al. reported the addition of $\mathrm{Al}$ metal powder into the 
polyethylene oxide to affect the electrical conductivity of the coatings [8]. $\mathrm{Cu}$ and $\mathrm{Ni}$ metal powders were tailored in the epoxy resin to study the electrical and thermal behavior by Mamunya and his coworkers [9]. Kim et al. studied the effect of $\mathrm{Al}, \mathrm{Fe}$, and $\mathrm{Si}$ metal powders in a polymer film to produce a shielding effect from electromagnetic waves [10]. Improvement in mechanical properties via embedment of these metallic powders and others in the matrix was also reported by various researchers worldwide [4-13]. In general, these metallic additives in the coating alter the coating's conductive behavior and dielectric property, inhibit the diffusion of moisture, and provide protection by acting as a barrier coat, inhibiting agent, or sacrificial anode [13].

Titanium metal is highly corrosion-resistant, malleable, ductile, and mechanically as strong as stainless steel and the $9^{\text {th }}$ most abundant element on the earth's crust. Its density is three times lower than other metals used as additives for corrosion protection, such as zinc, copper, nickel, silver, and stainless steel, while comparable to aluminum. However, unlike aluminum, titanium resists highly acidic, alkaline, chloride, and bromide ions in an aqueous medium [14]. Since there is no metal corrosion, therefore no metal oxides are formed and hence no depletion of the metal. Other metals that also fall in the same category are zirconium, niobium, and hafnium. These are relatively less frequently found in nature and are expensive $[15,16]$. These qualities make titanium an ideal choice for use as a powder in polymeric corrosion protection coatings.

This work consists of enriching titanium, an exotic metal powder, into an epoxy resin in two different proportions. For the first time, to the best of our information, the anticorrosion performance of the titanium-enriched epoxy coatings was evaluated in the natural marine service environment of the southeastern coastal area of the China-Pakistan Economic Corridor, which was also augmented by salt spray testing. Performance analysis comprised the film hardness measurement by pencil test, adhesion measurement by the crosshatch-tape test, chemical and heat resistance test, and gloss measurement. Comparison of virgin epoxy coating and as-prepared titanium-enriched epoxy coatings was also performed. Failure analysis of all the coating systems was executed by scanning electron microscopy (SEM) and Fourier transform infrared (FTIR) spectroscopy. It is pertinent to highlight that electrochemical impedance spectroscopy (EIS) was not carried out due to the low resistance of the coating caused by metal embedment, which also decreased as a function of metal content. However, it was compensated by the salt spray testing, which is more reliable because of electrical properties governed by multiple factors that may not cofunction with the coating protection mechanism.

\section{Materials and Methods}

2.1. Development of Titanium Coatings. To develop titaniumenriched coatings, bisphenol A-type epoxy resin procured from Nippon Paints Ltd., Pakistan, was selected as a base material. Typical properties of the this epoxy resin were 450-500 g/epoxy equivalent weight, 8000-13000 Cp viscosity at $25^{\circ} \mathrm{C}, 2.00-2.22$ epoxide value, $1.07 \mathrm{~g} / \mathrm{cc}$ density, $0.5 \%$ water content, and $30^{\circ} \mathrm{C}$ flashpoint. Organic red (colors index no. 170) and zinc phosphate as pigments, talc and silica as fillers, polyamidoamine as a hardener, and xylene as a solvent were used. Titanium metal powder $(1-5 \mu \mathrm{m})$ provided by Captain and Company, Karachi 75530, Pakistan, was incorporated as $5 \%$ and $10 \%(w / w)$ into an epoxy resin matrix while maintaining a 3:1 weight ratio between the epoxy resin and the curing agent.

For the development of titanium-enriched epoxy coatings, precalculated amounts of $\mathrm{Ti}$ metal powder were dispersed in xylene with constant stirring for 30 minutes by a magnetic stirrer (MS300HS Misung Scientific Pvt. Limited). The resultant dispersion medium was mixed with epoxy resin and stirred for 2 hours to obtain a homogenous mixture. Subsequently, a polyamidoamine hardener was added and stirred for a further 30 minutes. Another epoxy coating system was prepared by employing all the additives as mentioned above and procedures except titanium metal powder and named as a virgin epoxy coating.

\subsection{Application of Virgin and Titanium-Impregnated Epoxy} Coatings. Mild steel test coupons $(10 \mathrm{~cm} \times 15 \mathrm{~cm}$ size $)$ were cut from a $3 \mathrm{~mm}$ thick mild steel sheet provided by Hinopak Motors Limited (Body Operation Plant), Pakistan, to serve as a substrate for applying epoxy coatings. First, these test coupons were thoroughly cleaned with degreasing solvents according to the SSPC-SP1 (April 2015) protocol for surface preparation [17]. Subsequently, scuffing was performed to remove unevenness and improve the adhesion. This was followed by dry sanding with 150 and 1000 grit sandpaper for scrubbing the surface. Afterward, test coupons were rinsed with deionized water and dried in hot air. Resultant coupons were then cleaned with ethanol, followed by the final cleaning with acetone.

Application of as-prepared epoxy coatings on clean, mild steel test coupons was carried out in two steps. The first coat of about 50 microns was applied and cured at room temperature for 24 hours. Subsequently, the second coat of about 40 microns was applied after roughing the first coat, followed by complete drying and curing in a dust-free environment. Dry film thickness was measured at five different points on each coated panel as per standard ASTM D1186 (July 2001) using an Elcometer 456 digital coating thickness gauge [18]. Dry film thickness data presented are the average of these five measurements.

2.3. Measurement of Coating Properties. The following properties of as-prepared virgin and titanium-impregnated epoxy coatings were measured.

2.3.1. Drying Time Measurement. Drying time was measured in minutes at room temperature by a set-to-touch time testing method as per the ASTM D1640/D1640M (Dec 2014) standard [19]. The coating was applied to the test coupon, and after a specified interval, the coating was lightly touched with the tip of the finger. The fingertip was then placed immediately on the clean glass piece to check for any coating transfer on the glass surface. 
2.3.2. Film Hardness Measurement by Pencil Test. The pencil test procedure as per the ASTM D3363 (Sep 2020) standard was performed to measure film hardness by the Guangzhou Biuged instrument pencil tester (Model SN 505009) [20]. Lead pencils of different hardness from 9B (softest) to $9 \mathrm{H}$ (hardest) were employed to test the hardness of applied coatings at an angle of $45^{\circ}$ with the help of a standard holder at a distance of $6 \mathrm{~mm}$. The test was repeated with different highgrade pencils until the scratch on the coating was marked.

2.3.3. Adhesion Measurement by Crosshatch-Tape Test. The ASTM D3359 (Feb 2017) method was used for the measurement of adhesion [21]. In this test, a crosscut was made by using a mechanical blade razor. Afterward, adhesion tape was struck upon the boxes, and the tape was removed by pulling progressively at an approximately $60^{\circ}$ angle. The surfaces with the intact boxes were observed using a magnifying glass.

2.3.4. Chemical Resistance Test. The chemical resistance test was performed according to ASTM D1308 (Dec 2020) [22]. A mixture of acetone, distilled water, ethyl alcohol, and acetic acid was dropped randomly on two sets of coated coupons. One set of the coated coupon was then covered with a watch glass while the second set was kept uncovered. After 24 hours at room temperature, both sets of test coupons were examined for any stain or patch that could lead to corrosion or any damage to the coated surface.

2.3.5. Heat Resistance Test. For this purpose, two sets of coated test coupons were placed in an oven at $180^{\circ} \mathrm{C}$. One set of the coated coupons was removed from the oven after 24 hours and immediately plunged into a container of distilled water for one hour. The second set of test coupons was removed after 48 hours and allowed to cool at room temperature. According to ASTM D2485 (March 2018), both sets of test coupons were examined for any failure of the coatings in terms of blistering, rusting, cracking, and loss of adhesion [23].

2.3.6. Coating Performance Evaluation. Two different methods, i.e., natural exposure testing and salt spray testing, were executed for the performance evaluation of these asprepared coatings. First, each dried and cured coated coupon was scribed with an $\mathrm{X}$, reaching the mild steel base, to test resistance against film corrosion. The backside and edges of each specimen panel were secured by dipping in molten wax, which has provided a thick protective layer to prevent premature coating failure. One set of the scribed coated test coupons was kept unexposed for control experiments.

2.3.7. Natural Exposure Testing. Natural exposure testing was performed according to standard ISO 8565 (July 2011) [24] at two test stations, i.e., the National Institute of Oceanography (NIO, latitude 24.48 and longitude 66.59) and the Karachi Port Trust (KPT, latitude 24.81 and longitude 66.97) located along the southeastern coastal area of the ChinaPakistan Economic Corridor in Karachi, Pakistan. The corrosivity of the selected atmospheric corrosion test stations was determined as per ISO 9223-9225 (Feb 2012) [25, 26].
The coated test coupons were mounted onto a wooden exposure rack using ceramic separators and steel nuts at an angle of $45^{\circ}$ facing towards the sea. Photographs of the coated test coupons were recorded before and after exposure to study the changes. The noteworthy changes occurred in the scribed region.

2.3.8. Salt Spray Testing. Salt spray testing was performed in compliance with the ASTM B117 (Nov 2019) method [27]. A salt spray chamber was used to provide a high humidity (95-98\%) environment and continuous salt spray (5 wt\% $\mathrm{NaCl}$ ) at $35^{\circ} \mathrm{C}$ with a $\mathrm{pH}$ range from 6.5 to 7.2 . The coated test coupons were placed on plastic racks at $30^{\circ}$ parallel to the principal direction of fog flow through the chamber.

2.3.9. Coating Performance Assessment. Visual examination of a coating's degradation pattern in the scribed area was performed in compliance with guidelines recommended by ISO 4628-part 1 (Jan 2016) [28]. The coated panels were periodically rated for blistering, rusting, and cracking, according to ISO 4628-parts 2, 3, and 4 (Jan 2016) [29-31]. The degree of filiform corrosion was assessed after the complete deterioration of coatings according to standard ISO 4628-part 10 (Jan 2016) [32].

2.3.10. Gloss Measurement. Gloss values of all coated test coupons were measured by a gloss meter (Horiba IG-330) for the pre- and postexposure states in the natural environment and salt spray chamber according to the standard ISO 2813 (Oct 2014) [33]. Samples were cleaned before gloss measurements were performed at a $60^{\circ}$ angle. A total of four measurements were made on every sample for each inspection. Each sample was rotated about $45^{\circ}$ in the plane after each measurement. The data presented is the average of the four measurements.

2.3.11. Coating Failure Analysis by Scanning Electron Microscopy (SEM) and Fourier Transform Infrared (FTIR) Spectroscopy. After natural exposure testing and salt spray testing, failure analysis of the coatings was carried out by scanning electron microscopy (SEM) and Fourier transform infrared (FTIR) spectroscopy. For comparison, a control (unexposed) coating was also analyzed.

For SEM, small pieces of $25 \mathrm{~mm} \times 25 \mathrm{~mm}$ dimensions were cut from the control and exposed test coupons with complete care to prevent the damage or loss of the coating from the surface. After gold sputtering, the SEM micrographs were captured by using a scanning electron microscope (JEOL 6380A). The microscope was operated at $15 \mathrm{kV}$ voltage and $10^{-7}$ Torr vacuum.

FTIR spectroscopy was used to study the chemical changes in the exposed and unexposed coatings. Coating samples were prepared in $\mathrm{KBr}$ pellet form. A Shimadzu 8900 Fourier transform infrared spectrophotometer equipped with Omnic software, running in transmission mode from 4000 to $400 \mathrm{~cm}^{-1}$ range with 10 scans and $4 \mathrm{~cm}^{-1}$ resolution, was employed to obtain the FTIR spectra. 
TABLE 1: Codes for some frequently used terms of this study.

\begin{tabular}{lcc}
\hline S no. & Codes & Description \\
\hline 1. & $\mathrm{~T}_{0}$ & Virgin bisphenol A-type epoxy coating system without titanium \\
2. & $\mathrm{~T}_{5}$ & $5 \%(w / w)$ titanium-impregnated bisphenol A-type epoxy coating system \\
3. & $\mathrm{~T}_{10}$ & $10 \%(w / w)$ titanium-impregnated bisphenol A-type epoxy coating system \\
4. & $\mathrm{NIO}$ & Marine test station located at the National Institute of Oceanography \\
5. & $\mathrm{KPT}$ & Marine test station located at the Karachi Port Trust \\
6. & $\mathrm{SST}$ & Salt spray testing \\
\hline
\end{tabular}

TABle 2: Comparison of different properties of virgin epoxy coating and titanium-embedded epoxy coatings applied to mild steel.

\begin{tabular}{lcccccc}
\hline Sample codes* & $\begin{array}{c}\text { Dry film thickness } \\
(\mu \mathrm{m})\end{array}$ & $\begin{array}{c}\text { PVC } \\
(\%)\end{array}$ & $\begin{array}{c}\text { Volume of Ti metal powder } \\
(\%)\end{array}$ & $\begin{array}{c}\text { Drying time } \\
(\text { minutes })\end{array}$ & $\begin{array}{c}\text { Pencil hardness** } \\
\text { Adhesion loss } \\
(\%)\end{array}$ \\
\hline $\mathrm{T}_{0}$ & 82 & 19.53 & 0 & 140 & $4 \mathrm{H}$ & 69 \\
$\mathrm{~T}_{5}$ & 80 & 21.12 & 1.2 & 122 & $5 \mathrm{H}$ & 16 \\
$\mathrm{~T}_{10}$ & 86 & 22.81 & 2.4 & 110 & $5 \mathrm{H}$ & 4.76 \\
\hline
\end{tabular}

${ }^{*} \mathrm{~T}_{0}$ : virgin epoxy coating; $\mathrm{T}_{5}: 5 \%$ titanium-embedded epoxy coating; $\mathrm{T}_{10}: 10 \%$ titanium-embedded epoxy coating. ${ }^{* *}$ As per ASTM specifications: the softest pencil is $6 \mathrm{~B}$ and the hardest pencil is $6 \mathrm{H}$.

TABLE 3: Results of chemical resistance testing of the virgin epoxy coating and titanium-embedded epoxy coatings in open and covered conditions as per ASTM D1308.

\begin{tabular}{lcccc}
\hline \multirow{2}{*}{ Coating systems* $^{*}$} & Open condition & \multicolumn{2}{c}{ Chemical resistance test Grade** $^{* *}$} & Closed/covered condition \\
\hline $\mathrm{T}_{0}$ & A slight change in color with a loss in gloss & Passed (B) & Blister with color change and loss in gloss & Failed (D) \\
$\mathrm{T}_{5}$ & No change in color & Passed (A) & A slight change in color & Passed (B) \\
$\mathrm{T}_{10}$ & No change in color & Passed (A) & A slight change in color & Passed (B) \\
\hline
\end{tabular}

${ }^{*} \mathrm{~T}_{0}$ : virgin epoxy coating; $\mathrm{T}_{5}: 5 \%$ titanium-embedded epoxy coating; $\mathrm{T}_{10}: 10 \%$ titanium-embedded epoxy coating. ${ }^{* *}$ ASTM specifications: accepted (A and $\left.\mathrm{B}\right)$, failed (C and D).

\section{Results and Discussion}

\subsection{Appraisal of Virgin and Titanium-Impregnated Epoxy} Coatings' Properties. Some frequently used terms and a comparison of different properties of virgin and titaniumimpregnated epoxy coatings applied to a mild steel substrate are presented in Tables 1 and 2. Dry film thickness, \% pigment volume concentration (PVC), \% volume of Ti metal powder, drying time, pencil hardness, and adhesion loss of $\mathrm{T}_{0}, \mathrm{~T}_{5}$, and $\mathrm{T}_{10}$ coatings were measured. Earlier work has shown that drying comprises many time-consuming physical and chemical reactions, including polymerization, evaporation of the organic solvent, and oxidation reaction of the resin [34-37]. It is influenced by variables like light, temperature, nature of the substrate, the thickness of the film, and air movement $[34,35]$. Results indicated that the drying time of the epoxy coatings was decreased with the addition of metal powder in the order $\mathrm{T}_{0}>\mathrm{T}_{5}>\mathrm{T}_{10}$. These results are in agreement with other researchers who had reported that the incorporation of the different metallic fillers on a micro- and a nanoscale had decreased the curing time of the coating [35-37]. PVC is an essential tool for coatings and is responsible for the gloss and hiding power. PVC values of as-prepared epoxy coatings were increased with the increase of the Ti amount.

The results of the pencil hardness test have indicated that the $T_{5}$ and $T_{10}$ coatings were hard compared to the $T_{0}$ coat- ing. The addition of the titanium metal powder in various percentages has increased the film's hardness compared to the $\mathrm{T}_{0}$ coating. In general, the hardness of the polymeric film improves when reinforced with different particles. Because the interphase is usually formed when a metal ion is diffused into the organic matrix, this results in a multilayered system that increases the toughness of the polymeric film and inhibits the diffusion of corrodents [37]. The present study agreed well with the findings of other researchers who have reported that modified coatings showed better pencil resistance than unmodified coatings [35-38].

Results of the adhesion measurement by the crosshatchtape test as per ASTM D3359-09 have indicated that \% adhesion losses for the $T_{5}$ and $T_{10}$ coatings were less than those for the $T_{0}$ coating. $T_{10}$ coating with a higher percentage of titanium metal powder showed better performance and adhesion. This higher adherence may be due to increased cross-linkages in the polymeric network formed after the addition of the metal powder $[35,39]$. A literature survey showed that the modification could improve interphase adhesion in epoxy resin [3538]. Present results matched the findings of other researchers who reported that coatings modified by metal addition had exhibited better adhesion than unmodified coatings [35-41].

Table 3 has shown chemical resistance testing results of virgin and Ti-impregnated epoxy coatings under covered and uncovered conditions as per ASTM D1308. A visual 
TABLE 4: Results of heat resistance testing of the virgin epoxy coating and titanium-embedded epoxy coatings after 24 hours of heating followed by open-air exposure and dipping in distilled water as per ASTM D2485.

\begin{tabular}{lcccc}
\hline \multirow{2}{*}{ Coating systems* } & & \multicolumn{2}{c}{ Heat resistance test } & \\
& Placed in open air after heating & Grade & Dipped in distilled water after heating & Grade \\
\hline $\mathrm{T}_{0}$ & Fair color stability with roughness on the surface & Passed (B) & Loss of gloss and a slight change in color & Passed (B) \\
$\mathrm{T}_{5}$ & Better color stability & Passed (A) & Loss of gloss and good color stability & Passed (B) \\
$\mathrm{T}_{10}$ & Better color stability & Passed (A) & Loss of gloss and good color stability & Passed (B) \\
\hline
\end{tabular}

${ }^{*} \mathrm{~T}_{0}$ : virgin epoxy coating; $\mathrm{T}_{5}: 5 \%$ titanium-embedded epoxy coating; $\mathrm{T}_{10}: 10 \%$ titanium-embedded epoxy coating. ${ }^{* *}$ ASTM specifications: accepted (A and $\left.\mathrm{B}\right)$, failed (C and D).

TABLE 5: Defects rating as per ISO norms 4628 (parts 1-4) in the virgin epoxy coating and titanium-embedded epoxy coatings after natural exposure testing.

\begin{tabular}{lcccccccccc}
\hline \multirow{2}{*}{ Test stations } & \multicolumn{1}{c}{ Coating systems } & \multicolumn{9}{c}{ Defects observed after natural exposure testing } \\
& & $\mathrm{B}$ & $\mathrm{R}$ & $\mathrm{Cr}$ & $\mathrm{B}$ & $\mathrm{R}$ & $\mathrm{Cr}$ & $\mathrm{B}$ & $\mathrm{R}$ months & $\mathrm{Cr}$ \\
\hline \multirow{3}{*}{$\mathrm{NIO}$} & $\mathrm{T}_{0}$ & $2 \mathrm{~S}_{3}$ & 1 & 0 & $2 \mathrm{~S}_{4}$ & 2 & 0 & $3 \mathrm{~S}_{5}$ & 3 & 0 \\
& $\mathrm{~T}_{5}$ & 0 & 0 & 0 & $2 \mathrm{~S}_{3}$ & 1 & 0 & $2 \mathrm{~S}_{4}$ & 2 & 0 \\
& $\mathrm{~T}_{10}$ & 0 & 0 & 0 & 0 & 1 & 0 & $2 \mathrm{~S}_{2}$ & 2 & 0 \\
\hline \multirow{3}{*}{$\mathrm{KPT}$} & $\mathrm{T}_{0}$ & $2 \mathrm{~S}_{2}$ & 0 & 0 & $2 \mathrm{~S}_{3}$ & 1 & 0 & $3 \mathrm{~S}_{4}$ & 2 & 0 \\
& $\mathrm{~T}_{5}$ & 0 & 0 & 0 & $2 \mathrm{~S}_{2}$ & 0 & 0 & $3 \mathrm{~S}_{3}$ & 1 & 0 \\
& $\mathrm{~T}_{10}$ & 0 & 0 & 0 & 0 & 1 & 0 & $1 \mathrm{~S}_{1}$ & 1 & 0 \\
\hline
\end{tabular}

B: blistering; R: rusting; Cr: cracking; 0: no defect seen.

examination of these coatings was performed after the chemical resistance test. The performance of the coatings in terms of gloss loss, cracking, a sign of deterioration, and the removal of the coating from the surface was ascertained. Chemical resistance testing of the $\mathrm{T}_{0}$ coating under uncovered conditions has shown a slight change in color with gloss loss. However, $\mathrm{T}_{5}$ and $\mathrm{T}_{10}$ coatings have not demonstrated any staining after 24 hours of chemical exposure under uncovered conditions. Even any swelling or blister formation was not noticed on the surface of $\mathrm{T}_{5}$ and $\mathrm{T}_{10}$ coatings. Chemical resistance testing of $\mathrm{T}_{0}$ coating under covered conditions has recorded the appearance of the blister after 24 hours of exposure to the chemical mixture. The swelling was also observed with the loss of gloss and change in coating color.

Contrary to this, $\mathrm{T}_{5}$ and $\mathrm{T}_{10}$ coatings have shown a lighter stain on the coating surfaces with no swelling or blister. Thus, $\mathrm{T}_{5}$ and $\mathrm{T}_{10}$ coatings have demonstrated good resistance to the harsh chemical environment compared to the $\mathrm{T}_{0}$ coating. Furthermore, the present study agreed well with the findings of other researchers who have reported that metallic powder modified coatings have shown good chemical resistance than unmodified coatings when immersed in chemicals for a specific period [35-37].

Table 4 has shown results of heat resistance testing of virgin and Ti-impregnated epoxy coatings after 24 hours of heat treatment followed by open-air exposure and dipping in distilled water as per ASTM D2485. The hydrophilic nature of the epoxy leads to the absorption of water molecules from the atmosphere, which causes the swelling of the coating upon curing [42] - some defects formed after curing act as a passage for corrodents and moisture. Inorganic metallic fillers and pigments can form a miscible epoxy coating to cover all these flaws. These fine inorganic pigments fill up the cavities and imperfections and give a long-lasting coating performance by reducing the cracking and formation of uniform epoxy coating. These particles in the epoxy also act as interconnected molecules and form crosslinks during the curing process [40-43]. Results of current work have indicated better heat resistance of $T_{5}$ and $T_{10}$ coatings than the $\mathrm{T}_{0}$ coating. The present study agreed well with the work of Selvaraj and his coworkers, who studied the heat resistance of the titanate-cured epoxy. They observed only a slight color change at a higher temperature on the titanate-based coating. They concluded that titanate-based epoxy coating withstood the high temperature due to the inorganic linkage of the titanium [41].

\subsection{Performance Evaluation of Virgin and Titanium-} Impregnated Epoxy Coatings under Natural and Stimulated Marine Conditions

3.2.1. Visual Examination. Natural exposure testing at NIO and KPT has shown the formation of numerous small blisters along with some rusting on the surface of the $\mathrm{T}_{0}$ coating after three months of exposure. The size of the blisters and the intensity of rusting were increased with time. After nine months of exposure, rusting caused the deterioration of the coating system around the scribed region. Blisters of different sizes were also spread on the entire surface and near the edges of the exposed coated test coupons (Table 5 and Figure 1).

Natural exposure testing of the $\mathrm{T}_{5}$ coating at NIO has not shown any detectable rusting or blistering after three months of exposure. However, the gloss was reduced, and small blisters with a lower degree of rusting were observed after six 

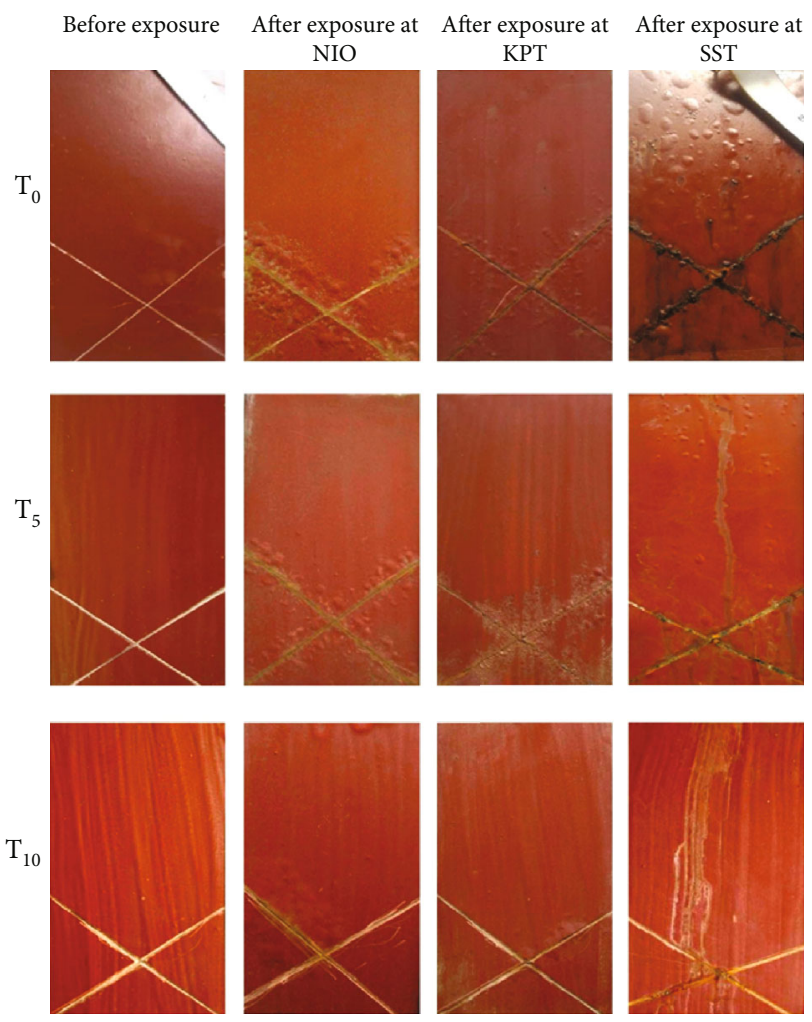

FIGURE 1: Visual appearance of the virgin epoxy coating $\left(\mathrm{T}_{0}\right)$ and the titanium-impregnated epoxy coatings $\left(\mathrm{T}_{5}\right.$ and $\left.\mathrm{T}_{10}\right)$ after natural exposure (NIO and KPT) and salt spray testing (SST).

months of exposure. An increase in the size of the blisters with visible rusting and gloss reduction was noted after nine months of exposure while cracking was not detected. At the KPT test station, the $\mathrm{T}_{5}$ coating has not shown any rusting or blistering after three months of exposure. Small blisters with a lower degree of rusting appeared after six months of exposure. Nine months of exposure has shown blisters with a higher degree of rusting and gloss reduction; however, cracking was not noted (Table 5 and Figure 1).

Natural exposure testing of the $\mathrm{T}_{10}$ coating at NIO has resulted in no detectable rusting or blistering after the initial three months of exposure. However, the gloss was reduced, and some rusting was noticed without blisters after six months of exposure. Moreover, blisters around the scribed region were recorded along with gloss reduction without cracking on the surface of applied coatings after nine months of exposure. At the KPT test station, no detectable rusting or blistering was observed after three months of exposure for $\mathrm{T}_{10}$ coating, while a lower degree of rusting was noticed after six months of exposure. In addition, minute blisters with noticeable rusting but without cracking were recorded in the $\mathrm{T}_{10}$ coating after nine months of exposure (Table 5 and Figure 1).

Comparison of the performance of $\mathrm{T}_{0}, \mathrm{~T}_{5}$, and $\mathrm{T}_{10}$ coatings after natural exposure testing at the NIO and KPT test stations has revealed that the coatings exposed at NIO deteriorated more (large size of blisters and a higher degree of rusting) than the coatings exposed at KPT. Early signs of degradation without cracking were noticed on all the coating systems exposed at NIO. This could be associated with the higher corrosivity of the NIO test station, as reported in previous work $[44,45]$.

Detailed defects observed in virgin and the titaniumimpregnated epoxy coatings after salt spray testing have been tabulated in Table 6. Large size blisters and severe rusting were noticed in the $\mathrm{T}_{0}$ coating (Table 6 and Figure 1). A comparison of the results has illustrated that $\mathrm{T}_{0}$ coating has demonstrated weak resistance in the salt spray chamber compared to the $\mathrm{T}_{5}$ and $\mathrm{T}_{10}$ coating systems.

A comparison of natural exposure and salt spray testing results revealed the better performance of $\mathrm{T}_{10}$ coating. It could be related to the higher percentage of the titanium metal powder in the $\mathrm{T}_{10}$ coating. A higher percentage of titanium metal powder has inhibited the corrodent from entering into the metal-coating interface and prohibited the growth of blisters. It may enhance the anticorrosion behavior of the epoxy coating.

Water diffusion through polymeric layers depends upon various factors such as stiffness of the polymer chain, crosslink density, and cohesive energy density. Moisture from the atmosphere and oxygen can easily fit into the voids created on the coating during curing. Due to the hydrophilic nature of the epoxy, this moisture quickly permeates into the substrate surface and develops blisters. The presence of the metal powder in the coating provides a barrier by filling these voids and prohibits the entrance of the moisture into the substrate surface, which in turn enhances the corrosion resistance of the coating $[34,40,42]$. Penetration of the salt fog into the flexible epoxy coating leads to the lifting of the coating and blister formation [40]. The present study demonstrated that the incorporation of titanium metal powder decreased the flexibility of the epoxy coating and prevented blister formation. These findings are consistent with the results reported in the literature [35-40].

3.2.2. Gloss Measurement. Gloss values of virgin and titanium-enriched coatings after natural exposure and salt spray testing are depicted in Figure 2. Before the exposure test, a higher value of gloss was observed for the $\mathrm{T}_{0}$ coating. In contrast, the modified coatings $\mathrm{T}_{5}$ and $\mathrm{T}_{10}$ have exhibited lower gloss due to roughness on the coating surface caused by the addition of irregularly shaped titanium metal particles [46]. A gloss of modified coatings may be improved by increasing coat thickness much more than the largest incorporated particle. Since this titanium metal powder-modified epoxy coating would be recommended for primer coats, which are at least 30 microns below the topcoat, sometimes even more if a surfacer is used, the final gloss of the coating system will not be affected.

For all the coating systems, maximum gloss reduction was observed after natural exposure testing at NIO followed by KPT and salt spray testing, while maximum gloss reduction occurred in the $\mathrm{T}_{0}$ coating. It could be associated with the higher corrosivity of the NIO test station, as reported earlier $[44,45]$.

The morphological changes that occur due to weathering on the surface can be studied by gloss change. The literature showed that the gloss of the epoxy-based coatings depends 
TABLE 6: Defect rating as per ISO norm 4628 (parts 1-4) in the virgin epoxy coating and titanium-embedded epoxy coatings after salt spray testing.

\begin{tabular}{|c|c|c|c|c|c|c|c|c|c|c|c|c|c|c|c|}
\hline \multirow{3}{*}{ Coating systems } & \multicolumn{15}{|c|}{ Duration of exposure and coating defects as per ISO norm 4628 (parts 1-4) } \\
\hline & \multicolumn{3}{|c|}{61 hours } & \multicolumn{3}{|c|}{98 hours } & \multicolumn{3}{|c|}{126 hours } & \multicolumn{3}{|c|}{201 hours } & \multicolumn{3}{|c|}{260 hours } \\
\hline & B & $\mathrm{R}$ & $\mathrm{Cr}$ & B & $\mathrm{R}$ & $\mathrm{Cr}$ & B & $\mathrm{R}$ & $\mathrm{Cr}$ & B & $\mathrm{R}$ & $\mathrm{Cr}$ & B & $\mathrm{R}$ & $\mathrm{Cr}$ \\
\hline $\mathrm{T}_{0}$ & $2 \mathrm{~S}_{3}$ & 1 & 0 & $2 \mathrm{~S}_{3}$ & 2 & 0 & $3 \mathrm{~S}_{4}$ & 3 & 0 & $4 \mathrm{~S}_{3}$ & 3 & 0 & $3 S_{4}$ & 3 & 0 \\
\hline $\mathrm{T}_{5}$ & 0 & 0 & 0 & $1 \mathrm{~S}_{1}$ & 0 & 0 & $3 \mathrm{~S}_{2}$ & 1 & 0 & $2 \mathrm{~S}_{3}$ & 1 & 0 & $3 S_{3}$ & 2 & 0 \\
\hline $\mathrm{T}_{10}$ & 0 & 0 & 0 & 0 & 0 & 0 & $1 S_{1}$ & 1 & 0 & $2 S_{1}$ & 1 & 0 & $2 \mathrm{~S}_{2}$ & 2 & 0 \\
\hline
\end{tabular}

B: blistering; R: rusting; Cr: cracking; 0: no defect seen.

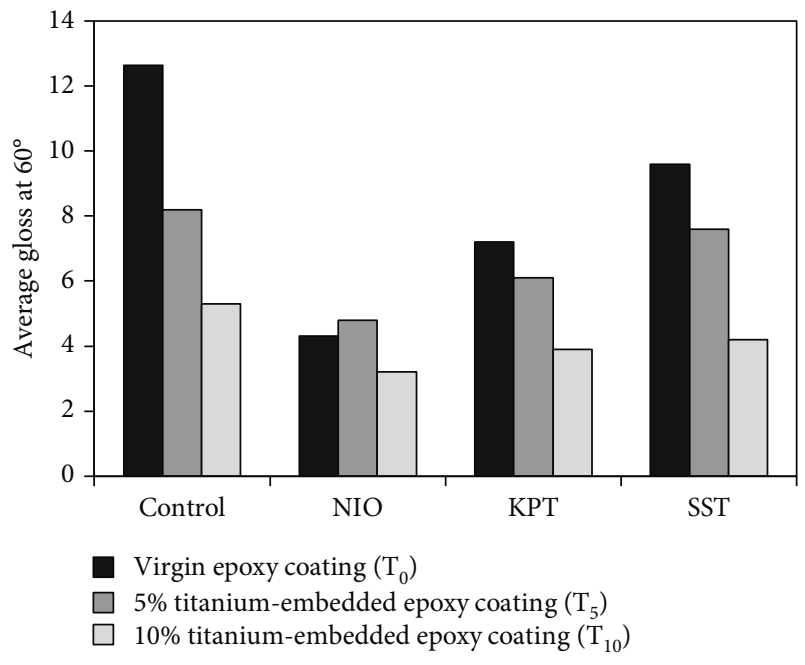

Figure 2: The gloss of the virgin epoxy coating $\left(\mathrm{T}_{0}\right)$ and the titanium-impregnated epoxy coatings $\left(\mathrm{T}_{5}\right.$ and $\left.\mathrm{T}_{10}\right)$ after natural exposure (NIO and KPT) and salt spray testing (SST).

on the formulation, surface smoothness, and refractive index of the coating. When exposed to sunlight, epoxy coatings lose gloss and fade [43-46]. Dutta et al. have concluded that weathering of the coating reduces the gloss value due to the destruction of the coating matrix, leading to the dismantling of cross-linkages among the organic units of the coating [47]. Malshe and Waghoo have proposed that gloss reduction in the epoxy coating may be due to the degradation of the aromatic matrix and secondary hydroxyl groups [48]. Yang and his coworkers have reported that the marine environment has caused a higher reduction in the gloss of the applied coating as compared to the salt spray testing due to sunlight and harsh atmospheric pollutants [49]. Bano and coworkers have also observed that in the epoxy coating, maximum gloss reduction was after natural exposure testing compared to salt spray testing [43]. The findings of the current study are in complete agreement with these reported results.

\subsection{Coating Failure Analysis}

3.3.1. Scanning Electron Microscopy. SEM micrographs have depicted that surfaces of the unexposed $\mathrm{T}_{0}, \mathrm{~T}_{5}$, and $\mathrm{T}_{10}$ coatings were even and had no defects. However, after natural exposure testing at $\mathrm{NIO}$, the surface of the $\mathrm{T}_{0}$ coating was severely roughened, and an acicular lepidocrocite product was noticed. This may be due to the complete degradation of the $\mathrm{T}_{0}$ coating system and corrosion of the underlying mild steel. Natural exposure testing at KPT and salt spray testing showed that the $\mathrm{T}_{0}$ surface was damaged and irregular (Figure 3). Natural exposure testing of the $\mathrm{T}_{5}$ coating system at NIO has indicated an uneven surface with crack formation on the surface. Natural exposure testing at KPT and salt spray testing have also induced the deprivation of the coating surface characteristics and roughened surfaces (Figure 3). Natural exposure testing of the $\mathrm{T}_{10}$ coating at $\mathrm{NIO}$ and KPT has instigated minor demolition of the coating surface characteristics. For salt spray testing, $\mathrm{T}_{10}$ coating surface characteristics did not appear to be significantly different from the unexposed sample features (Figure 3).

A comparison of the SEM results has indicated that the $\mathrm{T}_{0}, \mathrm{~T}_{5}$, and $\mathrm{T}_{10}$ coatings exposed at NIO and KPT deteriorated more than the coatings tested by SST. It was also found that the performance of the $\mathrm{T}_{10}$ coating was better than the $\mathrm{T}_{5}$ and $\mathrm{T}_{0}$ coatings. A good correlation between SEM studies and gloss measurements was also observed. Generally, degradation of the binder in coating results in an irregular surface and formation of cracks. It has been reported that the addition of modifiers affects the stability of the binders. These modifiers form stable oxide layers with the metal-coating interface and reduce the penetration of corrodents, thus reducing the corrosion process $[43,50,51]$. The present study agreed well with these findings.

3.3.2. Fourier Transform Infrared Spectroscopy. The FTIR spectrum of the unexposed $\mathrm{T}_{0}$ coating has shown a broadband due to $\mathrm{O}-\mathrm{H}$ stretching near $3439 \mathrm{~cm}^{-1}$. The bands at $2926 \mathrm{~cm}^{-1}$ and $2858.51 \mathrm{~cm}^{-1}$ have indicated the aromatic $\mathrm{CH}$ stretching and aliphatic $\mathrm{CH}$ stretching, respectively. The absorption at $1647 \mathrm{~cm}^{-1}$ corresponded to the crosslinking of polyamide with the epoxy group. The signal at $1485 \mathrm{~cm}^{-1}$ has indicated the C-C stretching of the aromatic nucleus, while the band from 1500 to $1600 \mathrm{~cm}^{-1}$ has exhibited $\mathrm{C}=\mathrm{C}$ stretching in the aromatic nucleus. Bending of $\mathrm{CH}$ in $\mathrm{CH}_{2}$ and $\mathrm{CH}_{3}$ groups was vibrated at $1463 \mathrm{~cm}^{-1}$ and $1384 \mathrm{~cm}^{-1}$, respectively. The aliphatic C-O stretching was observed at $1028 \mathrm{~cm}^{-1}$, while the signal at $873 \mathrm{~cm}^{-1}$ was due to the out-of-plane bending of two adjacent hydrogens of paradisubstituted aromatic. Bands at $534 \mathrm{~cm}^{-1}$ and $460 \mathrm{~cm}^{-1}$ were due to the COC bending vibration and COC stretching vibration, respectively (Figure 4) [42, 43, 49, 5153].

FTIR spectra of the unexposed $\mathrm{T}_{5}$ and $\mathrm{T}_{10}$ coatings have depicted bands at $3444 \mathrm{~cm}^{-1}$ and $2924 \mathrm{~cm}^{-1}$ due to $\mathrm{O}-\mathrm{H}$ 

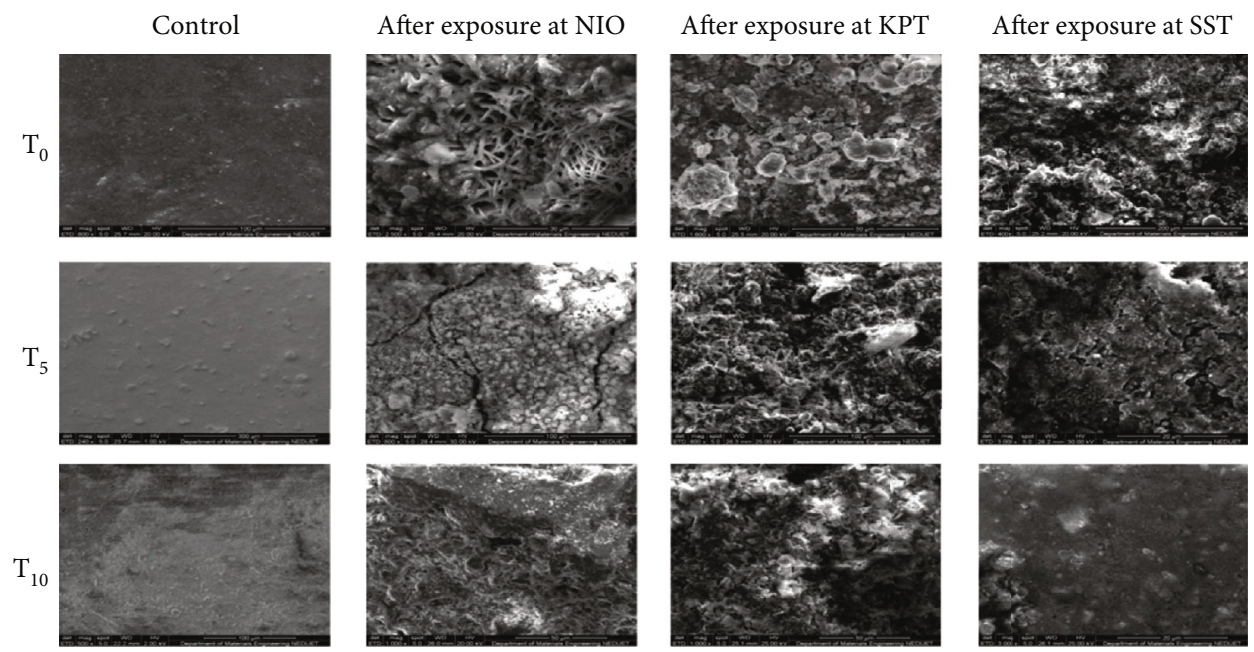

FiguRE 3: Scanning electron micrographs of virgin epoxy coating $\left(\mathrm{T}_{0}\right)$ and the titanium-impregnated epoxy coatings $\left(\mathrm{T}_{5}\right.$ and $\left.\mathrm{T}_{10}\right)$ after natural exposure (NIO and KPT) and salt spray testing (SST).

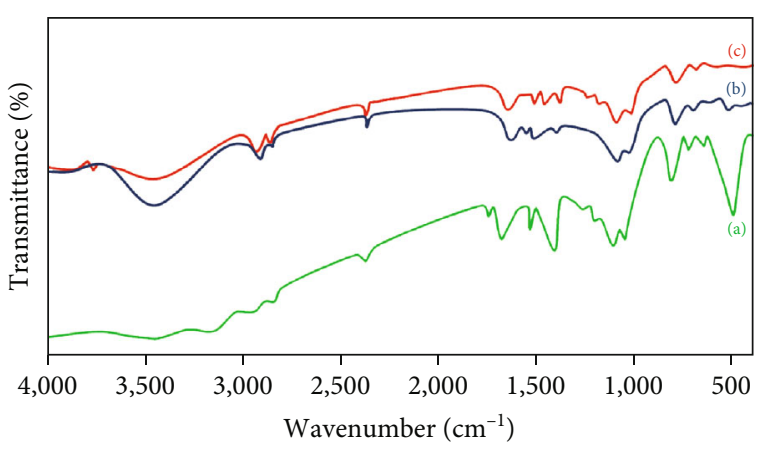

FIGURE 4: Infrared spectra of (a) virgin epoxy coating, (b) $5 \%$ titanium-embedded epoxy coating, and (c) $10 \%$ titaniumembedded epoxy coating before natural exposure testing at NIO.

stretching and aromatic $\mathrm{C}-\mathrm{H}$ stretching vibrations, respectively. Aliphatic C-H stretching was observed at $2858 \mathrm{~cm}^{-1}$, while $\mathrm{C}=\mathrm{C}$ stretching of the benzene ring (aromatic) was noted from 1500 to $1600 \mathrm{~cm}^{-1}$. The $\mathrm{C}-\mathrm{O}$ stretching vibrations of aryl ether at $1244 \mathrm{~cm}^{-1}$ and aliphatic C-O stretching at 1031 and $1087 \mathrm{~cm}^{-1}$ were recorded. The $\mathrm{C}-\mathrm{O}-\mathrm{C}$ bending vibration was noticed from the 500 to $600 \mathrm{~cm}^{-1}$ range $[45$, $49,51,52]$. The titanium metal powder has not shown any signal in the FTIR spectra due to the limitation of the technique and the appearance of the signal in the far IR region (Figure 4) [42, 43, 54].

The $\mathrm{T}_{0}$ coating after natural exposure testing at the NIO and KPT test stations and after salt spray testing has demonstrated variations in the same IR regions (Figures $5-7$ ). These changes were observed to be independent of the type of testing involved. A decrease in the band intensity of aliphatic C-O stretching in the $1028-1035 \mathrm{~cm}^{-1}$ region was noticed. The decrease in the signal intensity of the $\mathrm{C}-\mathrm{O}$ stretching vibration of aryl ether near $1250 \mathrm{~cm}^{-1}$ was observed after salt spray testing and natural exposure testing at the KPT test station, while at the NIO test station, this absorption entirely disappeared. The decrease in the band intensity of the aromatic

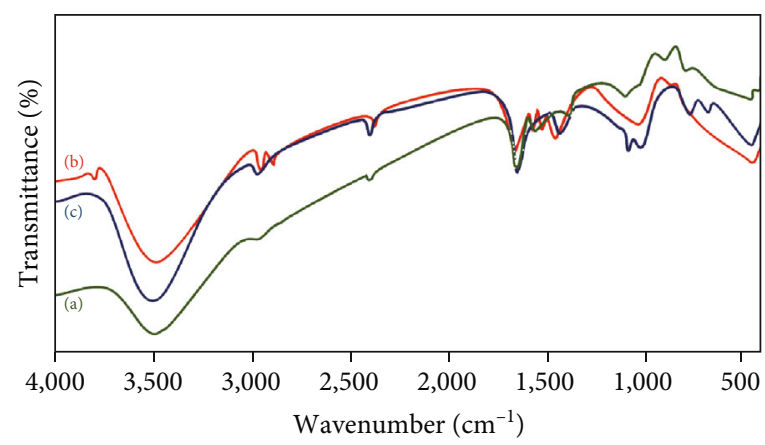

FIgURE 5: Infrared spectra of (a) virgin epoxy coating, (b) 5\% titanium-embedded epoxy coating, and (c) $10 \%$ titaniumembedded epoxy coating after natural exposure testing at NIO.

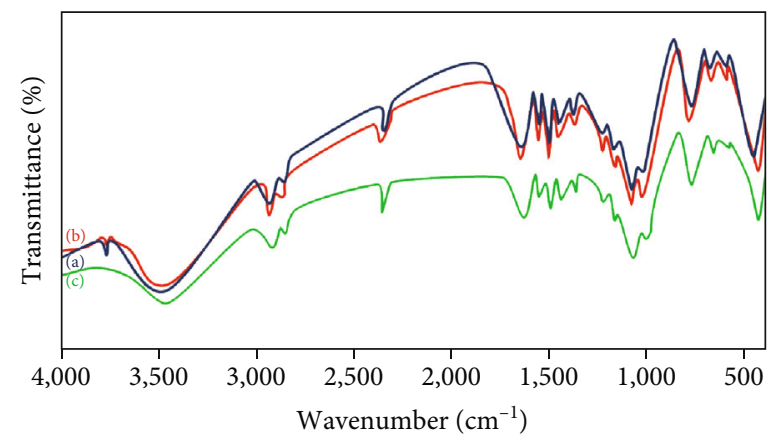

FIGURE 6: Infrared spectra of (a) virgin epoxy coating, (b) 5\% titanium-embedded epoxy coating, and (c) $10 \%$ titaniumembedded epoxy coating after natural exposure testing at KPT.

nucleus having $\mathrm{C}=\mathrm{C}$ stretching in the region of 1500 $1600 \mathrm{~cm}^{-1}$ was also observed, while new signals appeared in the $1620-1800 \mathrm{~cm}^{-1}$ region $[42,43,52,53]$.

FTIR spectra of $T_{5}$ and $T_{10}$ coatings after natural exposure testing at the NIO and KPT test stations and after salt spray testing are illustrated in Figures $5-7$. The stretching of Ti-O and Ti-O-Ti bonds was vibrated at about $450 \mathrm{~cm}^{-1}$ 


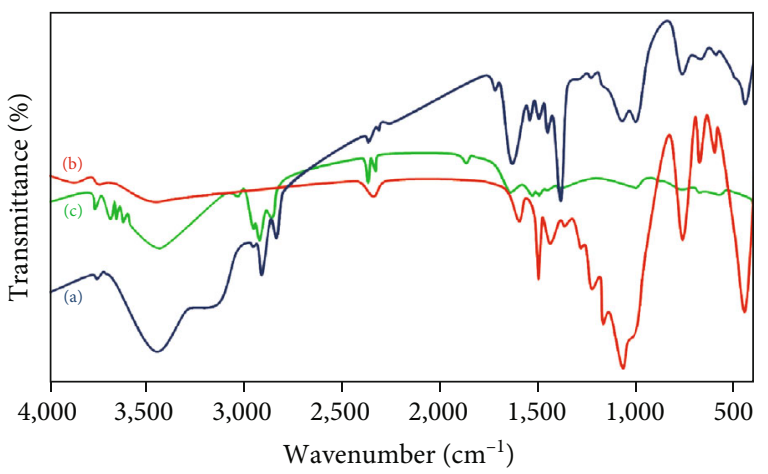

FIGURE 7: Infrared spectra of (a) virgin epoxy coating, (b) $5 \%$ titanium-embedded epoxy coating, and (c) $10 \%$ titaniumembedded epoxy coating after 260 hours of salt spray testing.

and $2370 \mathrm{~cm}^{-1}$, respectively. Intensities of these absorbance signals were increased upon the addition of the metal powders due to the formation of bonds between the titanium metal powder and the epoxy resin. These observations are consistent with the reported results of Wang et al., Alam et al., and Zhang and Li $[39,55,56]$. These have described that an increase in the stoichiometric discrepancies in the epoxy would increase the transmittance. At the same time, the vibration of $\mathrm{Ti}-\mathrm{O}$ was noticed in the lower wavenumber region from 550 to $638 \mathrm{~cm}^{-1}$, which formed during the curing process of the epoxy coating [39]. Signals became blunt, and intensities were decreased for the aliphatic $\mathrm{C}-\mathrm{O}$ stretching vibration at $1244 \mathrm{~cm}^{-1}$ and $\mathrm{C}=\mathrm{C}$ stretching in the region from 1500 to $1600 \mathrm{~cm}^{-1}$. This may be due to the mass loss and chain scission in the epoxy resin $[43,53]$. New absorbance signals in the region from the 1620 to $1740 \mathrm{~cm}^{-1}$ have indicated the presence of $\mathrm{C}=\mathrm{O}$ stretching from amides and ketones of oxidation products. The broadband at the $3400 \mathrm{~cm}^{-1}$ region showed the stretching vibration of the $\mathrm{OH}$ group linked to $\mathrm{Ti}(\mathrm{Ti}-\mathrm{OH})$.

A comparison of the results has revealed that the $\mathrm{T}_{0}$ coating suffered from maximum degradation. In contrast, the addition of titanium metal powder has improved the efficiency and performance of the coatings in the natural as well as in the accelerated environment. Higher degradation of the coatings was observed in natural exposure due to the harsh effect of UV rays and a variety of environmental pollutants [43]. In addition to showing variations in the similar IR regions, a comparison of the results has also demonstrated that the maximum deterioration of all the coatings was observed after the natural exposure on both marine test stations as compared to salt spray testing. These findings are consistent with the previous literature $[42,43,50,52,53]$. It has been reported that the decrease in the band intensities, chain scissoring, and loss of cross-linkage occur due to weathering of the epoxy coating in the natural environment [54-57]. Bellenger and Verdu has reported the formation of ketone products by the carbonyl band at $1728 \mathrm{~cm}^{-1}$, while Paterson has reported the aldehyde-based products $[58,59]$. Both of these reactions have indicated the formation of water molecules by the dehydration reaction of the hydroxyl groups.

\section{Conclusions}

In this study, titanium, an exotic metal powder, was incorporated in two different proportions as a corrosion-resistant additive in epoxy resin for good corrosion resistance performance in-service conditions of the southeastern coastal area of the China-Pakistan Economic Corridor. Resultant titanium-enriched coatings have demonstrated excellent properties, including film hardness by pencil test, adhesion measurement by the crosshatch-tape test, chemical and heat resistance, gloss consistency, and exemplary performance in natural exposure and salt spray testing. Furthermore, this work also reveals a comparison of the degradation process in the virgin and titanium-impregnated epoxy coating by employing SEM and FTIR techniques. Owing to good properties and performance results, these titanium-enriched epoxy coatings may find application against atmospheric corrosion for highly corrosive marine sites located worldwide and for the shipping industry.

\section{Data Availability}

The data used to support the findings of this study is included within the article.

\section{Conflicts of Interest}

The authors declare no conflict of interest.

\section{Acknowledgments}

Many thanks are due to M. Akram from Hino Pak Motors Limited for the valuable support. The authors much acknowledge Dr. Munawwar Saleem, Director General Institute of Oceanography, and Fayyaz Rasool, Manager Marine Pollution Control Department KPT. Many thanks are due to Omer Itrat and Khurram Shahzad from Nippon Paints Ltd., Pakistan.

\section{References}

[1] S. C. Tjong and H. Chen, "Nanocrystalline materials and coatings," Nanocrystalline materials and coatings, vol. 45, no. 1-2, pp. 1-88, 2004.

[2] C. Sun, J. Dai, H. Zhang, F. Zhang, and N. Zhang, "Preparation and characterization of spherical titania and their influence on self-cleaning and anticorrosion properties of acrylic resin," Progress in Organic Coatings, vol. 128, pp. 21-31, 2019.

[3] M. Yeganeh, M. Omidi, and T. Rabizadeh, "Anti-corrosion behavior of epoxy composite coatings containing molybdateloaded mesoporous silica," Progress in Organic Coatings, vol. 126, pp. 18-27, 2019.

[4] W. Brostow, M. Dutta, and P. Rusek, "Modified epoxy coatings on mild steel: tribology and surface energy," European Polymer Journal, vol. 46, no. 11, pp. 2181-2189, 2010.

[5] L. Shuan, Corrosion resistance and tribological properties of epoxy coatings reinforced with well-dispersed graphene, advances in carbon nanostructures, Intech Open, 2016.

[6] L. Mardare and L. Benea, "Development of anticorrosive polymer nanocomposite coating for corrosion protection in 
marine environment," IOP Conference Series: Materials. Science and Engineering, vol. 209, p. 012056, 2017.

[7] B. Wetzel, F. Haupert, K. Friedrich, M. Q. Zhang, and M. Z. Rong, "Impact and wear resistance of polymer nanocomposites at low filler content," Polymer Engineering and Science, vol. 42, no. 9, pp. 1919-1927, 2002.

[8] M. Muszynska, H. Wycislik, and M. Siekierski, "Composite polymeric electrolytes based on poly(ethylene oxide) matrix and metallic aluminum filler," Solid State Ionics, vol. 147, no. 3-4, pp. 281-287, 2002.

[9] Y. P. Mamunya, V. V. Davydenko, P. Pissis, and E. V. Lebedev, "Electrical and thermal conductivity of polymers filled with metal powders," European Polymer Journal, vol. 38, no. 9, pp. 1887-1897, 2002.

[10] S. W. Kim, Y. W. Yoon, S. J. Lee et al., "Electromagnetic shielding properties of soft magnetic powder-polymer composite films for the application to suppress noise in the radio frequency range," Journal of Magnetism and Magnetic Materials, vol. 316, no. 2, pp. 472-474, 2007.

[11] X. Shi, T. A. Nguyen, Z. Suo, Y. Liu, and R. Avci, "Effect of nanoparticles on the anti-corrosion and mechanical properties of epoxy coating," Surface and Coatings Technology, vol. 204, no. 3, pp. 237-245, 2009.

[12] R. N. Jagtap, P. P. Patil, and S. Z. Hassan, "Effect of zinc oxide in combating corrosion in zinc-rich primer," Progress in Organic Coatings, vol. 63, pp. 389-394, 2008.

[13] N. Kouloumbi, G. M. Tsangaris, and S. Kyvelidis, Metal filled composites as protective coatings against marine corrosion, $\mathrm{S}$. A. Campbell, N. Campbell, and F. C. Walsh, Eds., Development in marine environment, Woodhead Publishing, 1998.

[14] Does titanium rust? If so, why?https://www.quora.com/Doestitanium-rust-If-so-why.

[15] C. H. R. V. S. Nagesh, C. H. S. Rao, N. B. Ballal, and P. K. Rao, "Mechanism of titanium sponge formation in the Kroll reduction reactor," Metallurgical and Materials Transactions B, vol. 35, pp. 65-74, 2004.

[16] Y. Shao, Y. Li, Y. Du, and F. Wang, "Enhancement of the protectiveness of epoxy coatings with surface-modified nano-titanium particles," Corrosion, vol. 62, no. 6, pp. 480-490, 2006.

[17] SSPC, SSPC-SP1: solvent cleaning - a method for removing all visible oil, grease, soil, drawing and cutting compounds, and other soluble contaminants, The Society for Protective Coatings, Pittsburgh, Pennsylvania, 2015.

[18] ASTM, ASTM D1186: standard test methods for nondestructive measurement of dry film thickness of nonmagnetic coatings applied to a ferrous base (withdrawn 2006), ASTM International, West Conshohocken, PA, 2001.

[19] ASTM-D1640/D1640M, Standard test methods for drying, curing, or film formation of organic coatings, ASTM International, West Conshohocken, PA, 2014.

[20] ASTM, ASTM D3363, standard test method for film hardness by pencil test, ASTM International, West Conshohocken, PA, 2020.

[21] ASTM D3359, standard test methods for rating adhesion by tape test, ASTM International, West Conshohocken, PA, 2017.

[22] ASTM D1308, standard test method for effect of household chemicals on clear and pigmented coating systems, ASTM International, West Conshohocken, PA, 2020.

[23] ASTM D2485, standard test methods for evaluating coatings for high temperature service, ASTM International, West Conshohocken, PA, 2018.
[24] ISO 8565, metals and alloys: atmospheric corrosion testinggeneral requirements, ISO, Geneva, Switzerland, 2011.

[25] ISO 9223, corrosion of metals and alloys: corrosivity of atmospheres- classification, determination and estimation, ISO, Geneva, Switzerland, 2012.

[26] ISO 9225, corrosion of metals and alloys: corrosivity of atmospheres-measurement of environmental parameters affecting corrosivity of atmospheres, ISO, Geneva, Switzerland, 2012.

[27] ASTM B117, standard practice for operating salt spray (fog) apparatus, ASTM, West Conshohocken, PA, 1997.

[28] ISO 4628-1, "paints and varnishes-evaluation of degradation of coatings-designation of quantity and size of defects, and of intensity of uniform changes in appearance," in Part 1: general introduction and designation system, CEN, Brussels, 2016.

[29] ISO 4628-2, "paints and varnishes-evaluation of degradation of coatings-designation of quantity and size of defects, and of intensity of uniform changes in appearance," in Part 2: assessment of degree of blistering, CEN, Brussels, 2016.

[30] ISO 4628-3, "paints and varnishes - evaluation of degradation of coatings-designation of quantity and size of defects, and of intensity of uniform changes in appearance," in Part 3: assessment of degree of rusting, CEN, Brussels, 2016.

[31] ISO 4628-4, "paints and varnishes-evaluation of degradation of coatings-designation of quantity and size of defects, and of intensity of uniform changes appearance," in Part 4: assessment of degree of cracking, CEN, Brussels, 2016.

[32] ISO 4628-10, "paints and varnishes-evaluation of degradation of coatings designation of quantity and size of defects, and of intensity of uniform changes in appearance," in Part 10: assessment of degree of filiform corrosion, CEN, Brussels, 2016.

[33] ISO 2813, "paints and varnishes-determination of gloss value at 20 degrees," in 60 degrees and 85 degrees, CEN, Brussels, 2014.

[34] S. Devasahayam, "Towards improving wet adhesion in a metal oxide polymer coating system," Journal of Applied Polymer Science, vol. 99, pp. 3318-3327, 2006.

[35] A. Cerit, M. E. Marti, U. Soydal, S. Kocaman, and G. Ahmetli, "Effect of modification with various epoxide compounds on mechanical, thermal, and coating properties of epoxy resin," International Journal of Polymer Science, vol. 7, 13 pages, 2016.

[36] S. Palraj, M. Selvaraj, K. Maruthan, and G. Rajagopal, "Corrosion and wear resistance behavior of nano-silica epoxy composite coatings," Progress in Organic Coatings, vol. 81, pp. 132-139, 2015.

[37] A. Chaudhari, V. Gite, S. Rajput, P. Mahulikar, and R. Kulkarni, "Development of eco-friendly polyurethane coatings based on neem oil polyetheramide," Industrial Crops and Products, vol. 50, pp. 550-556, 2013.

[38] W. Kai, L. Jiarun, X. Weichen, Y. Liangmin, H. Baorong, and L. Min, "Enhanced inter-phase adhesion and anti-corrosion properties in epoxy coating modified via acrylic resin," International Journal of Electrochemical Science, vol. 11, pp. 89148926, 2016.

[39] X. Z. Zhang and Y. J. Li, "Effects of nano-sized titanium powder on the anti-corrosion property of epoxy coatings on steel," Kemija u Industriji, vol. 63, pp. 317-322, 2014.

[40] S. Devasahayam, "Effect of moisture ingress on adhesion energy in a metal oxide polymer system," Journal of Applied Polymer Science, vol. 99, pp. 2052-2061, 2006.

[41] M. Selvaraj, K. Maruthan, S. Palraj, and G. Venkatachari, "Preparation and characterization of thermally stable epoxy- 
titanate coatings," Progress in Organic Coating, vol. 67, pp. 339-347, 2010.

[42] M. G. Gonzalez, J. C. Cabanelas, and J. Baselga, “Applications of FTIR on epoxy resins-identification, monitoring the curing process, phase separation and water uptake, in infrared spectroscopy," Infrared Spectroscopy - Materials Science, Engineering and Technology, pp. 261-284, IntechOpen Limited, London, UK, 2012.

[43] H. Bano, A. Mahmood, and S. A. Kazmi, "Atmospheric corrosion resistance of epoxy duplex coated electrogalvanized steel exposed in marine, industrial and urban sites at Pakistan," Journal of the Chemical Society of Pakistan, vol. 39, pp. 560$571,2017$.

[44] I. Jamil, H. Bano, J. G. Castano, and A. Mahmood, "Characterization of atmospheric corrosion near the coastal areas of Arabian Sea," Materials and Corrosion, vol. 69, pp. 898-960, 2017.

[45] I. Jamil, H. Bano, J. G. Castano, A. Mahmood, and F. Zafar, "Atmospheric corrosion patterns of electrogalvanized mild steel in east southern coastal areas of CPEC," Materials and Corrosion, vol. 69, pp. 1870-1878, 2018.

[46] D. Piazza, A. F. Baldissera, S. R. Kunst et al., "Influence of the addition of montmorillonite in an epoxy powder coating applied on carbon steel," Materials Research, vol. 18, no. 5, pp. 897-903, 2015.

[47] S. Dutta, N. Karak, and T. Jana, "Evaluation of Mesua ferrea L. seed oil modified polyurethane paints," Progress in Organic Coating, vol. 65, no. 1, pp. 131-135, 2009.

[48] V. C. Malshe and G. Waghoo, "Weathering study of epoxy paints," Progress in Organic Coating, vol. 51, no. 4, pp. 267272, 2004.

[49] X. F. Yang, T. Liu, J. Li, S. Qiub, and H. Zhao, “Anticorrosive behavior of a zinc-rich epoxy coating containing sulfonated polyaniline in $3.5 \% \mathrm{NaCl}$ solution," Royal Society of Chemistry Advances, vol. 8, pp. 13237-13247, 2018.

[50] M. Morcillo, R. Barajas, S. Feliu, and J. Bastidas, "A SEM study on the galvanic protection of zinc-rich paints," Journal of Materials Science, vol. 25, pp. 2441-2446, 1990.

[51] M. R. Bagherzadeh, T. Mousavinejad, E. Akbarinezhad, and M. Ahmadi, "Highly protective performance of water based epoxy coating loaded with self-doped nanopolyaniline synthesized under supercritical $\mathrm{CO}_{2}$ condition," Progress in Organic Coating, vol. 77, no. 11, pp. 1977-1984, 2014.

[52] D. G. Weldon, Failure Analysis of Paints and Coatings, John Wiley \& Sons, 2009.

[53] H. Bano, A. Mahmood, M. I. Khan, and S. A. Kazmi, "Synergistic corrosion mitigation appraisal of coal tar epoxy duplex coating system by spectroscopic and microscopic techniques," Arabian Journal for Science and Engineering, vol. 39, pp. 67836791, 2014.

[54] F. X. Perrin, M. Irigoyen, E. Aragon, and J. Vernet, "Evaluation of accelerated weathering tests for three paint systems: a comparative study of their aging behavior," Polymer Degradation and Stability, vol. 72, no. 1, pp. 115-124, 2001.

[55] B. Wang, S. Wei, Y. Wang et al., "Effect of milling time on microstructure and properties of nano-titanium polymer by high-energy ball milling," Applied Surface Science, vol. 434, pp. 1248-1256, 2018.

[56] M. A. Alam, E. M. Sherif, and S. M. Al-Zahrani, "Mechanical properties and corrosion behavior of different coatings fabricated bydiglycidyl ether of bisphenol-A epoxy resin and aradur-3282 curing agent," International Journal of Electrochemical Science, vol. 8, pp. 8388-8400, 2013.

[57] P. Vijayan, H. El-Gawady, Y. Mohamed, and M. Al-Maadeed, "A comparative study on long term stability of self-healing epoxy coating with different inorganic nanotubes as healing agent reservoirs," Express Polymer Letters, vol. 11, no. 11, pp. 863-872, 2017.

[58] V. Bellenger and J. Verdu, "Oxidative skeleton breaking in epoxy amine networks," Journal of Applied Polymer Science, vol. 30, no. 1, pp. 363-374, 1985.

[59] J. Paterson, "The mechanism of the thermal degradation of aromatic amine cured glycidyl ethertype epoxide resins," Journal of Applied Polymer Science, vol. 19, no. 6, pp. 1539-1547, 1975. 